\title{
The Importance of Including the Value of Soil in Metropolitan Planning Strategies
}

\author{
Alessandra Maria Pandolfi \\ Dipartimento di Architettura e Studi Urbani \\ Politecnico di Milano \\ 20133 Milano, Italy
}

\begin{abstract}
Metropolitan systems are developing rapidly, growing in number and size, frequently disregarding essential planning guidelines, primarily in terms of spatial distribution. According to UN predictions, urban and metropolitan systems will markedly expand in the next 3 decades, raising shared concerns in distribution management, determining inequalities between social classes, even in developed countries. Soil becomes, then, the most important economic asset, since correct spatial distribution rules will significantly influence the perception of value in urban and metropolitan systems, determining long term effects on decision-making processes.
\end{abstract}

Keywords-Economic sustainability in urban planning, Real estate values, Soil protection and awareness, Spatial distribution rules, Urban rent.

\section{INTRODUCTION}

Cities development policies have often focused on goals related to the increase of urban values [1], not only in terms of quality (of life and environment), but also in the economic and real estate component, expressing themselves through a variety of tools and strategies. Achieving an increase in economic values at the urban/metropolitan level implies a long process, which should start with collective investments in urban development [2]. However, public finance cutbacks, that involved recently many countries, after the economic crisis, no longer allows several metropolitan systems to benefit of the same amount of resources that were available even in the recent past. Experts in urban and metropolitan development know very well that the involvement of private investors becomes increasingly important in this instance. Actually, two categories of interventions can be implemented in this sense, without supporting unsustainable expansion trends: strategies to create new functions, that attract new potential metropolitan users, possibly by renovating abandoned or decaying areas, or to promote the regeneration of existing public facilities, above all, where the greatest social and environmental issues raise [3].

Constantly pursuing for a balance between interests that are permanently and universally at stake in all urban and metropolitan systems, each city strategy should be read in objective terms, and should start from expressing equality judgments, largely acceptable at every and each level [4]. A possible solution to the political problem of reorganizing metropolitan systems in efficient ways is choosing between multiple policies, each linked to a specific interest and ranging within two opposite approaches (socio-economic and spatial), implying a clear and transparent assessment of the financial benefits distribution and the relationship between community and individual values $[4,5]$. This need is urgent in the actual occurrence, following the issues related to public policies aiming at implementing and managing urban developments, or in support of private initiatives.

Metropolitan strategies need Economic principles and tools to be equitable and efficient, requiring multifaceted and differentiated knowledge to be organized [6]. Metropolitan studies, comparably to many other disciplines, use economic tools, without being economic sciences. Economy is basically based on reading the goals that drive human behaviors and their relationship with resources (individual, collective or public), that can be called 'economic goods' (essentially, based on their scarcity, appropriability/exclusivity and utility). Individuals and communities allocate use values to resources and agree in setting laws, rules, customs, and rights to use or own goods, highlighting the economic nature of sciences dealing with economic goods, their planning and evaluation. In the complex world of economic goods, one special class of assets takes central stage in metropolitan studies: nonmovable, spatialized properties, that can be private (e.g. real estate assets) or public (e.g. infrastructures), depending on who owns their property rights [5].

Experts in urban and metropolitan development management sciences must be able to rely on a large set of skills [7], because of the increased complexity of urban systems that are to be analyzed and evaluated to develop correct planning strategies, sometimes facing situations that are totally different from the past. The task of urban and metropolitan planners is, therefore, once complexity has been explored [8], to select the mission and the goals that should be accomplished, starting from the postulate of sustainability. The analysis and assessment process is, consequently, to be based on the choice of the elements to be evaluated and the procedures to be adopted, inspired to the principles of problem-solving (based on domain, problem types and solution detection) to unravel any issues that arise along the way [9]. It could be said that urban planning in metropolitan systems is based on a typically circular approach (focused on the actions of recognizing/identifying, defining, representing, solving and systematizing knowledge): we could declare, in essence, that it is based on the definition of the domain of the problem, which is nothing more than the determination of the value of metropolitan assets contributing to determine the spatial configuration of metropolitan systems [10].

In the actual scenario, the definition of value and its evaluation have been refined, to the point that they become the basis of economic processes and the essence of regulatory 
postulates [5]. The purpose of value assessment, in general, is, therefore, the estimation of metropolitan assets, according to their specific features, both in quantitative and qualitative terms, involving, on one hand, data from technical and analytical disciplines and, on the other hand, information related to the economic quantification of the asset values. Economic values should be, then, described through a synthetic way of expressing the overall value of the asset itself [9], thanks to the use of the most synthetic language existing, that is the numerical expression, joined by a unit of monetary measure, which is the benchmark in the evaluation field. Without describing in details the wider debate that revolves around the role and orientation that assessment disciplines play in our society [10], we can assume that it is not just a question of economic value, but it refers to the cultural implication of using innovative and reliable techniques, available in the real estate appraisal sciences at national and international level [11].

\section{URBAN RENT, CITY QUALITY AND PUBLIC} DEBTS

Soil, which characterizes each region through its distinctive features, is a composite element of great complexity and fragility, an irreplaceable factor that generates peculiarities and diversity, an exceptional source of opportunity and energy, a resource that strongly influences any living form and, of course, also people, their activities, their perceptions, and their abilities. The term is designated by using a capitalized initial letter, to indicate the importance of this concept and its declination as a specific resource, corresponding to the meaning represented by the environment/landscape dichotomy. In fact, the attribution to the Soil of the status of resource proposes a setback in the perspective generally attributed to it, moving from a condition of simple background, that supports anthropic and natural activities, to a multidimensional space, endowed with specific features and levels of complexity, that are of its own.

\section{A. What is Urban rent?}

The debate on urban rent, the implementation of public functions and the contribution of private individuals, has long been considered a central element of urban planning strategies, and also in the implementation of equitable tools [5]. The debate has come to several conclusions on this issue in recent years, which infer the need for all components, that enjoy the benefits of urban development, to contribute to the development of cities [12]: this is also one of the most innovative, but limiting outcomes, already starting from some of the most recent case studies in 1980s and 1990s.

In this context, there were several attempts to understand the relationship between land rent and competitive advantage in positional terms, which led to the creation of a sequence of theories to be applied to urban development, without considering political or philosophical positions on the fairness of involving private entities in the public city construction, which is part of a process in which decision-makers can determine the so called 'ius aedificandi' and the rebalancing of interests for a long term sustainable development.

The origin and phenomenology of the value of urban land are strongly rooted in the production factors of the classical economy theory, in which rent is meant as the component of wealth generated by the exclusive right to use a natural asset. Rent exists, then, because of a natural or artificial cause, replicating competition, in the shape of a relative or absolute monopoly that limits production [5].

The Soil (agricultural or urban) is, actually, an asset, whose availability is strongly limited (its quantity can be hardly increased), as each portion has specific production resources, that, once used, are basically irreproducible. Ricardo developed a rent theory that referred to agricultural land, determined by the product surplus compared to the least productive plots. Unexpectedly, though Ricardo developed a concept of strategic importance for urban planning, he didn't consider position as the advantage given by the process of urban development.

The positional rent is quite different from any other benefit (in terms of premium for the risk of the business initiative), thanks to the portion of the advantage coming to the higher utilization relevance, added by public facilities (which is an extra surplus over rent) [11]. In addition to Ricardo's models, there are also the theories from Von Thünen, Alonso and Marx, to classify the creation of urban value in terms of rent, in which Marshall identified the community component, that he called 'public value'.

The starting point of the modern debate could be traced back in Ebenezer Howard's famous 'Garden City', which was intended to appropriate the profits coming from the construction of the city to produce a urban system, in which open (green belts) and built spaces are harmoniously balanced. This idea was, then, promoted by the New Towns Development Act, which led to the development of several examples of rebalancing market interests and urban quality, also in public spaces [13]. Analyzing the garden cities of Letchworth and Welwin, the multidisciplinary nature of the urban development process is highlighted by the mutual influence between formal and economic values, that leads to a better understanding of the urban rent trends, to create a correct taxation system, or to redistribute it, controlling factors that contribute to spatial distribution, preventing it from only reflecting speculative processes, rather than reaching targets of morphological quality and environmental sustainability (in a broader sense).

\section{B. City quality and public debt}

The conflict in not solved yet, however, for rent, surplus and profit are still central factors in the formulation of urban strategies, which found distinct solutions in different contexts, specifically, in terms of land management regulations [5]. For this reason, the relation between urban rent, settlement costs, Soil classes and the real estate market are so close, for the market value of assets is rooted in their production costs and the 'positional advantage' is a significant part of it. It is no longer acceptable to minimize the reciprocal relations between those factors, as that most of the differential advantage is due to position factors [11]. As a result, equitable policies can and should redistribute to the community some of the surplus and advantages related to public city development, that private developments normally benefit from. Then, evaluation becomes a central element in the definition of consistent rules, that should not over-affect the entrepreneurial initiative, while ensuring the correct redistribution of benefits and costs of 
urban development between public and private entities and enterprises [14].

Countries, in which the land administration system is now centered on a democratic system, that has reached full maturity, suffer from high public debt rates, which become a significant problem that local and national governments must face urgently [15]. This need has become even more obvious as a result of the dramatic economic crisis in the main developed countries and it has been marked by several laws about spending reviews (mainly, in Europe), in the last 10 years. E.g. in Italy, the need to reduce public debt had a significant impact on the role of local public authorities, due to reductions in transfers coming from the central government, a problem that has increased considerably, compared to the intensification in tasks that administrations face, to the growth in expectations and demands from citizens (in terms of public services and city quality), and to the natural process of welfare privatization, followed by increasing examples of partnership between public and private entities, created to reply and adapt to the ever-changing and increasing fragmentation of social demand [11].

The issues met by urban and metropolitan planning sciences, in general, in the last two decades now, needs new tools and applications [15]. The solution to this long-standing problem is to be found, for many authors, in the control of urban rent, above all, using equitable tools to redistribute the economic surplus given by the decision on the 'ius aedificandi', by unleashing its distribution from the mere spatial allocation, to adopt innovative answers in the metropolitan planning, considering the interests involved in the relevant decisions.

\section{THE IMPORTANCE OF SOIL AS PRODUCTION FACTOR}

In this complex context, Soil becomes the central element of metropolitan planning actions, as it is a scarce resource, even in sustainable terms (environmental, social and economic), it is not incrementable, and it is difficult to reproduce (mainly, in positional terms), which has a determining influence on real estate market trends and the implementation of metropolitan policies. Soil becomes, then, a key element, both in terms of urban rent and profitability of the positional surplus. For this reason, equitable metropolitan strategies could play a key role in terms of efficient land use allocation, that is consumed every year, and also in preventing and mitigating risks and managing outcomes that come from environmental hazards.

\section{A. Soil and risk management}

Risk and environmental damage denote a multidimensional connotation, whose complex characterization is linked to natural factors, as well as technical, political, cultural and sociological ones [16]. The concept of risk, in the most comprehensive formulations, consists of three different factors: hazard (resulting from the intrinsic features of damaging sources, which can be natural or artificial), vulnerability (linked to the characteristics of subjects and objects that are affected by a catastrophic event) and exposure (the quantity and quality of subjects and objects that are exposed to hazards).
The concept of environmental damage has changed considerably and substantially in the recent past [17] and could be further strengthened and supported by recognizing Soil as a resource, a factor that would significantly increase the compensation of damage, acknowledging its intrinsic value, as happened in some cases for water. Among different types of risks, the hydrogeological and climate hazards represent the most serious threats to Soil, mainly, in countries facing serious delays in the implementation of related protection policies. Landslides, floods and other hydrogeological events are the main natural risks in most countries [18]. Other climate related natural events can be linked to fires, or other meteorological events (e.g. monsoons and typhoons).

Metropolitan planning strategies should ensure goals related to Soil protection [19], water restoration, correct water use and management [20], as well as the protection of the related environmental components, by regulating the opportunities and the implementation tools that contribute to this. In this regard, tools and laws for interregional and international management of risks can significantly help preventing Soil losses, though main difficulties could happen in establishing agreements between different regions and countries [18]. This should be implemented through innovative policies introducing efficiency in planning, to prevent dramatic devastations that usually come from contingent emergency measures. In this complex general state of defenselessness, the anthropic factors essentially linked to the misuse of Soil contribute to this general state of vulnerability. The recent floods that affected many countries around the world in the last 2-3 months are just the latest in a long record of hydrogeological failures which, in addition to claiming victims, cause extensive damage to households, infrastructures and economic-productive activities, creating substantial issues of significant social importance [16].

\section{B. Managing Soil transformations}

In terms of urban planning, the integrity of regions can only be safeguarded by controlling the transformation of Soil from its natural condition to built spaces, where people can live, study, work, and travel. This modification of the original features of Soil is generally irreversible and causes equally incontrovertible alterations in the overall balance of ecosystems, even in the anthropic ones [19]. On one hand, transformations, that Soil constantly undergoes for non-natural reasons, cannot be completely recovered, since men themselves, by their own presence, change the features of the environment in which they live, adapting those characteristics to their own goals, needs and intentions [21]. On the other hand, however, it is necessary to check every alteration in the Soil structure and the spatial distribution on time, to minimize the negative effects of inappropriate modifications [22].

To achieve a sufficiently effective control of land transformations, it is necessary to know, with adequate accuracy, the Soils features and the components standing on different areas, that constitute every region, and the distinctive elements that characterize human activities, to compare their compatibility and to identify where it is most suitable to allocate every and each function [23]. Such a way of addressing the issues related to land use increases planning tools effectiveness [24], as areas and regions involved in 
development strategies are accurately analyzed using sustainable evaluation tools, that assess transformations in terms of environmental, social and economic appropriateness [23]. This consideration is clearly focused on the awareness of the spatial dimension of physical resources and, particularly, of Soil, as well as the recognition of the information value that resources themselves comprise, in terms of cognitive understanding of the process that fostered their creation [25].

According to the economic vision, moreover, chemical elements, living organisms and ecosystems are not resources as they are, but they become supplies only when there is a demand for using them and for satisfying people needs, i.e. when there is a technology that allows people to profitably using them [26]. Thus, for people, the concept of resource fluctuates with the degree of historical, technological and social development and with the economic value ascribed to resources at any given time.

That is to say, natural resources are subject to market trends, which attribute them a 'price' that reflects their utility. Over time, therefore, the value of a resource will fluctuate in its integral parts, that determine its utility [26], i.e. in the kind of demand, from which, then, the amount to be used in the different production cycles is determined which, then, influences the way in which resources will be used.

This specific economic process covers the whole resource extension, however, as far as Soil is concerned as natural capital, compared to other components of the system, such as air and water, the association of processes that lead to the establishment of the corresponding 'price' [27] is somehow less acknowledged than the procedure related to other resources [26]. In fact, the analysis of the Soil consumption was not a particularly participated research field in planning sciences, considering the most significant studies were only considering its geographical nature, although this type of enquiries has generally a common definition of Soil as a 'rare resource', an asset that is likely to be 'consumed' according to economists, or to be 'used' in relation to the lexicon of urban analysts [21].

\section{Public properties and urban development}

In this complex background, the issues about exploiting goods are still related to the public city management, which represent yet another opportunity never fully captured by many countries and that equitable planning strategies could, once again, be negotiating, creating a broad consent around it [28]. Considering this, it is necessary to recognize that, due to the extensive complications in finding resources for the implementation of public functions in many countries [15], the real estate properties of local and national administrative authorities can no longer have a static function in urban development. They must become part of a dynamic process of developing and enhancing local conditions, including the integration of existing tools with the implementation of management practices. Moreover, public assets must become, in turn, a resource, as both economic, social and service value, and as the nucleus and engine of the redevelopment of urban and metropolitan regions and the consolidation of public finances [15].

In this sense, the need for a collaboration between public and private actors, which allows the local economic system to take full advantage of the sedimentation and time stratification of investments, becomes crucial. Community investments will essentially determine, as they always did in the past, the critical structures of the value system (including real estate properties), that characterize our regions, thanks to the intervention of private entities, which, contributing with their own action, can lead to a further development and increase a similar and complex system.

Opportunities to reuse or optimize public assets and properties, available both in large numbers and often represented by properties of well-known quality and interest, represent a fundamental moment for the owning public bodies and for the local communities [7]. In fact, many urban and metropolitan regions have thousands of real estate assets (including World Heritage sites recognized by UNESCO) that could represent a significant contribution to both the national economy (which could thus take advantage of the benefits associated with the rational use of those resources), and for single communities, which, because of, above all, the dynamics related to the phenomenon of globalization, could rely on an extra economic foundation to create suitable local development conditions.

In addition, as many experts in this field point out, the public assets of the different urban and metropolitan regions can be an opportunity both to promote new systems of regional and institutional aggregation, and to foster the local 'value' meant as 'relational capital', both to answer the questions of the new demographic scenario and, finally, to identify and implement a lever for the renewal of urban systems and regions.

From this point of view, public assets represent a fundamental element of urban and metropolitan systems, both as properties for the communities (meant as 'widespread' shareholders), as a cost-cutting part of national and local identity, and as a representation of a substantial proportion of national 'common goods'. Therefore, public assets and properties in general (linear and punctual infrastructures, real estate properties, natural goods, such as maritime and water possessions) are a fundamental component of the so-called 'fixed social and collective capital' of countries [26] and constitute the 'critical mass' of urban and metropolitan systems, functional to the local society, constituting the material element ('containers' in the case of buildings, 'support' in the case of land plots) of infrastructure policies and the allocation of collective fixed capital, in relation to the needs expressed by the evolution of the economic and social systems.

\section{CONCLUSIONS}

The concept of Soil defense, generally declined in terms of protection from the aggression of occurrences and events, mainly of catastrophic nature, is usually conceived in a rather restrictive way: in a comprehensive sense, this notion could be better conceived as a complementary idea to the concept of Soil consumption in all its different components (including the dimension of excessive depletion and waste). This concept comes from the fact that urban and metropolitan regions, that hosts and endures every anthropic activity, are constantly consumed and should be protected from the indiscriminate use that activities could commit [25].

The resource status generally assumes the meaning of capital, quality, or asset, and is commonly qualified as the set 
of natural features of urban and metropolitan regions, that can be exploited by people to their advantage [23]. Soil and its spatial features are also generally to be considered a resource, that is hardly recognized and reputed as such, since the disciplines that have dealt with it, especially in the past, have historically proposed a conception of space linked to an infinite development, that is not extinguishable, as for many other natural resources.

To overcome this outdated vision, we should refer to all the important philological concepts linked to the exhaustiblerenewable dichotomous combination: these two adjectives have been joined to the term 'resource' recently (since 1980s), as an innovative result of the awareness that is linked to the limitless theme of sustainability [12]. The quality of Soil as a resource is recognized by some authors, who describe it as the capacity of Soil to perform its functions, attitude linked to the use that is carried out by people.

A possible decrease in the quality level is linked to the deterioration caused by all actions and processes of degradation and environmental pressure [21]. There are two fundamental categories of pressures, often synergistic and difficult to separate, i.e. stress sources of natural matrix, linked to climatic changes, morphological upheavals, increased water rates following floods, and of anthropic development, coming from the over-exploitation of agriculture, from the losses caused by urbanization, from the modification of endogenous features for chemical and organic fertilization, from the disposal of waste of several different sources.

Therefore, safeguarding Soil as a resource means recognizing its peculiarities and geological and naturalistic importance. Just as the international regulations comprehend references to the conservation of specific habitats and particularly rare animal species, they should also recognize the extraordinariness of the pedological capital [25] (in a comprehensive sense) and protect it in its finiteness, starting from the awareness that Soil cannot be used in an infinite flow. International regulations should also recognize that we must also have to consciously address every issue, especially regarding urban and metropolitan planning, with the utmost awareness of the sustainable development objective.

The idea of Soil consumption is rooted in the tendencies (natural or anthropic) to the transformation of urban and metropolitan systems, that challenge the heritage of physical factors, eroding a more or less substantial part of them, in a generally irreversible way [26]. One of the most overdue features of this occurrence is the amount of Soil that is generally consumed according to per capita functions, in an attempt to measure the real consistency of the consumption and assess whether it is simple use, excessive depletion or even waste, as for any other natural resource.

Of course, the lability of the limit between 'lawful' consumption, excessive depletion or waste engages the connotations of high instability, since the wide variety of local realities does not allow an effective evaluation comparison, except through the use of historical series. We must admit that also this type of comparison is ineffective, since every historical period has endorsed certain peculiarities in the use of urban and metropolitan regions, depending on the specific culture and the particular socio-economic conditions of that time [12].

To better define the recommendations that follow, it is necessary to clarify what is meant by consumption of Soil and what differentiates it from the concept of excessive depletion or waste. The concept of Soil consumption itself is revealed as the increasing uncertainty and inadequacy, in order to control the new sense of transformation processes taking place in the urban and metropolitan regions. In fact, urban and metropolitan planning strategies need to rebuild the concept of Soil consumption [25], conceiving it as an indicator of the impact that different uses (and the processing activities associated with them) make of resources, considering their non-reproducible dimension [18].

The concept of excessive depletion or 'waste', which is substantially different from the idea of consumption, is, then, mentioned in order to support the need to dedicate higher attention to this occurrence. It is important, subsequently, to manage urban and metropolitan planning strategies both through a quantification of all consumption occurrences (meant as withdrawals operated by human and natural activities on the environment, including Soil), both by qualitatively analyzing the peculiarities of urban and metropolitan regions, to assess their compatibility with different uses, and the model by which these expansive manifestations develop, in order to be able to identify better alternatives in terms of lower compromising.

In actual fact, Soil consumption, as such, is not necessarily a thoughtful drawback, because people, since they began to create permanent settlement and to deal with agricultural production enduringly, have acquired Soil from the natural environment, also to build larger villages and settlements (although, not without serious exceptions and considerable waste). The worrying components, that tend to distress the current disciplinary debate, are related to the threshold of the limit between consumption, excessive depletion and waste and the way in which such erosion is happening, which turned into the manifestations of an 'unnecessary consumption'. This concept becomes, therefore, central to the perception and understanding of the idea of 'waste', beyond the objective 'consumption' one.

Urban and metropolitan regions degraded by certain categories of catastrophic events could, actually, be seen in the innovative perspective of the waste of Soil, committed by natural occurrences, triggered by manifestations that cannot always be directly attributed to anthropic activities. In this regard, a considerable intensification in the occurrence of some damages can be better understood.

Similarly, anthropic disasters (such as industrial accidents, e.g. Bhopal in India in 1984 or Seveso in Italy in 1976, or events related to pollution and spillage and similar occurrences) can be easily translated into terms of waste of natural resources, including Soil, as they can compromise the natural capital itself at different levels and with different regeneration horizons. Considering this, the definition of Soil excessive depletion and waste could be recognized to any activity or event (natural or anthropic) that experienced specific levels of use of urban and metropolitan regions, that can affect irreparably their features and their ability to renovate and recreate themselves (for renewable resources, 
this will distress the regeneration process only during long periods of time, therefore, this king of excessive depletion makes renewable resources similar to the category of nonrenewables).

\section{REFERENCES}

[1] S. Wang, Z. Yang, and H. Liu, "Impact of urban economic openness on real estate prices: Evidence from thirty-five cities in China," in China Economic Review, Volume 22, Issue 1, March 2011, pp. 42-54.

[2] M. Bencardino, and A. Nesticò, "Demographic Changes and Real Estate Values. A Quantitative Model for Analyzing the Urban-Rural Linkages," in Sustainability, 2017, pp. 536-545.

[3] H. Amin-Tahmasbit, and A. Reza Saraf Jadidin, "A Scenario Planning of Urban Planning in the Municipality," in International Journal of Engineering Research \& Technology (IJERT), Volume 8, Issue 06, June 2019, pp. 1526-1534.

[4] A. Gabba, and S. Mattia, "I1 Contributo operativo dell'estimo nella urbanistica concertata," in Quaderni del Ce.S.E.T., 2009, available on www.fupress.net/index.php/ceset.

[5] S. Mattia, A. Oppio, and A. Pandolfi, "The role of evaluation tools in the urban policies for the development rights transfer/compensation: the isovalue maps for properties," in Aestimum, August 2, 2013, pp. 201-219, DOI: https://doi.org/10.13128/Aestimum-13133.

[6] M. Conconi, and A. Pandolfi, "Doing Something Scenario: Teaching Students an Incremental Approach to Design Strategies for Development Countries," in IJIRES Journal, Volume 5, Issue 6, November 2018, pp. 680-689.

[7] A. Contin, P. Paolini, and R. Salerno, "Innovative Technologies in Urban Mapping: Built Space and Mental Space," Sxi - Springer for Innovation book series (SXIINNO, volume 10), 2014, DOI: 10.1007/978-3-319-03798-1, ISBN 978-3-319-03797-4.

[8] P. Modi, and S. Shah, "Big Data Analysis in Urban Planning," in International Journal of Engineering Research \& Technology (IJERT), Volume 8, Issue 10, October 2019, pp. 355-359.

[9] M. Conconi, and A. Pandolfi, "Training Interior Designers to Project Feasibility Studies," in IJIRES Journal, Volume 5, Issue 6, November 2018, pp. 694-703.

[10] M. Conconi, and A. Pandolfi, "Project assessment and economic and financial sustainability determination for the Interior design," in 9th International Conference on Social Science and Humanities (ICSSH), $26^{\text {th }}-27^{\text {th }}$ December 2017, Bangkok, Thailand.

[11] Tegova, European valuation standards, 2016, available on https://www.tegova.org.

[12] R. Capello, "Urban rent and urban dynamics: The determinants of urban development in Italy," in The Annals of Regional Science, Volume 36, Issue 4, December 2002, pp. 593-611.

[13] B. Clark, "Ebenezer Howard And The Marriage Of Town And Country: An Introduction to Howard's Garden Cities of To-morrow," in Organization \& Environment, Volume 16, Issue 1, March 2003, pp. 87-97.
[14] Tavistock Institute, GHK, IRS, "The evaluation of socio-economic development: the guide," 2004, available on www.evalsed.info.

[15] H. DeSoto, "The mystery of capital: why capitalism triumphs in the West and fails everywhere else," Basics Books, 2000, New York.

[16] S. Mattia, A. Oppio, A. Poletti, and A. Pandolfi, "Modelling and Evaluating an Environmental Damage Scenario: Discussing an Assessment Model Predicted Through a Geographical Information System Procedure,” in Chemical Engineering Transactions, Volume 28, January 2012, pp. 241-246.

[17] S. Mattia, A. Oppio, and A. Pandolfi, "An assessment model for the environmental damage simulation through scenarios predicted with a Geographic information system," in Aestimum, August 2, 2013, pp. 459-477, DOI: https://doi.org/10.13128/Aestimum-13156.

[18] S. Mattia, A. Oppio, A. Poletti, and A. Pandolfi, "The environmental damage simulation and evaluation: discussing an assessment model predicted through a scenario procedure developed thanks to GIS tools,' in International Symposium of Sanitary and Environmental Engineering, 9th Ed. - SIDISA 2012 - Sustainable Technology for Environmental Protection, Milan, June 2012.

[19] G.D. Garrod, and K.G. Willis, "Economic Valuation of the Environment," Edward Elgar, 1999, Cheltenham UK.

[20] C.H. Green, and S.M. Tunstall, "The evaluation of river water quality improvements by the contingent valuation method," in Applied Economics, Volume 23, 1991, pp. 1135-1146.

[21] R. Gregory, S. Lichtenstein, and P. Slovic, "Valuing environmental resources: a constructive approach," in Journal of Risk and Uncertainty, n. 7, 1993, pp. 177-197.

[22] R. Gregory, and P. Slovic, "A constructive approach to environmental valuation," in Ecological Economics, n. 21, 1997, pp. 175-181.

23] A. Pandolfi, P. Campi, and L. Terlizzi, "Using the Geographica information systems for the quantitative and qualitative landscape analysis," in 9th International Conference on Social Science and Humanities (ICSSH), 26 ${ }^{\text {th }}-27^{\text {th }}$ December 2017, Bangkok, Thailand.

[24] M. Rehan Khan, and U. Ali, "Parametric Approach in the City Planning (Introduction to the Cellular Automata Simulation in the Future Cities and its Integration in the GIS Technology)," in International Journal of Engineering Research \& Technology (IJERT), Volume 8, Issue 06 , June 2019, pp. 1428-1433.

[25] A. Pandolfi, P. Campi, and L. Terlizzi, "GIS and landscape analysis," in PEOPLE: International Journal of Social Sciences, Special Issue Volume 3 Issue 1, pp. $629-643$

[26] D.W. Pearce, and R.K. Turner, "Economics of Natural Resources and the Environment," Johns Hopkins university Press, 1989, Baltimore USA.

[27] RICS, "Valuation of development land," 2008, available on https://www.rics.org/globalassets/rics-website/media/upholdingprofessional-standards/sector-standards/valuation/valuation-ofdevelopment-land-1st-edition-rics.pdf.

[28] A. Boardman, D. Greenberg, A. Vining, and D. Weimer, "Cost Benefit Analysis: Concepts and Practice,” Pearson Professional, 2005. 